US Army Corps of Engineers $s_{\circledast}$

Engineer Research and

Development Center

Unmanned Airborne System Support to Civil Works Flood Risk Management

\title{
Geospatial Accuracy of Small Unmanned Airborne System Data in the Coastal Environment
}

Robert L. Fischer, Jeffrey G. Ruby, Aaron J. Armstrong,

February 2019

Jarrod D. Edwards, Nicholas J. Spore, and Katherine L. Brodie

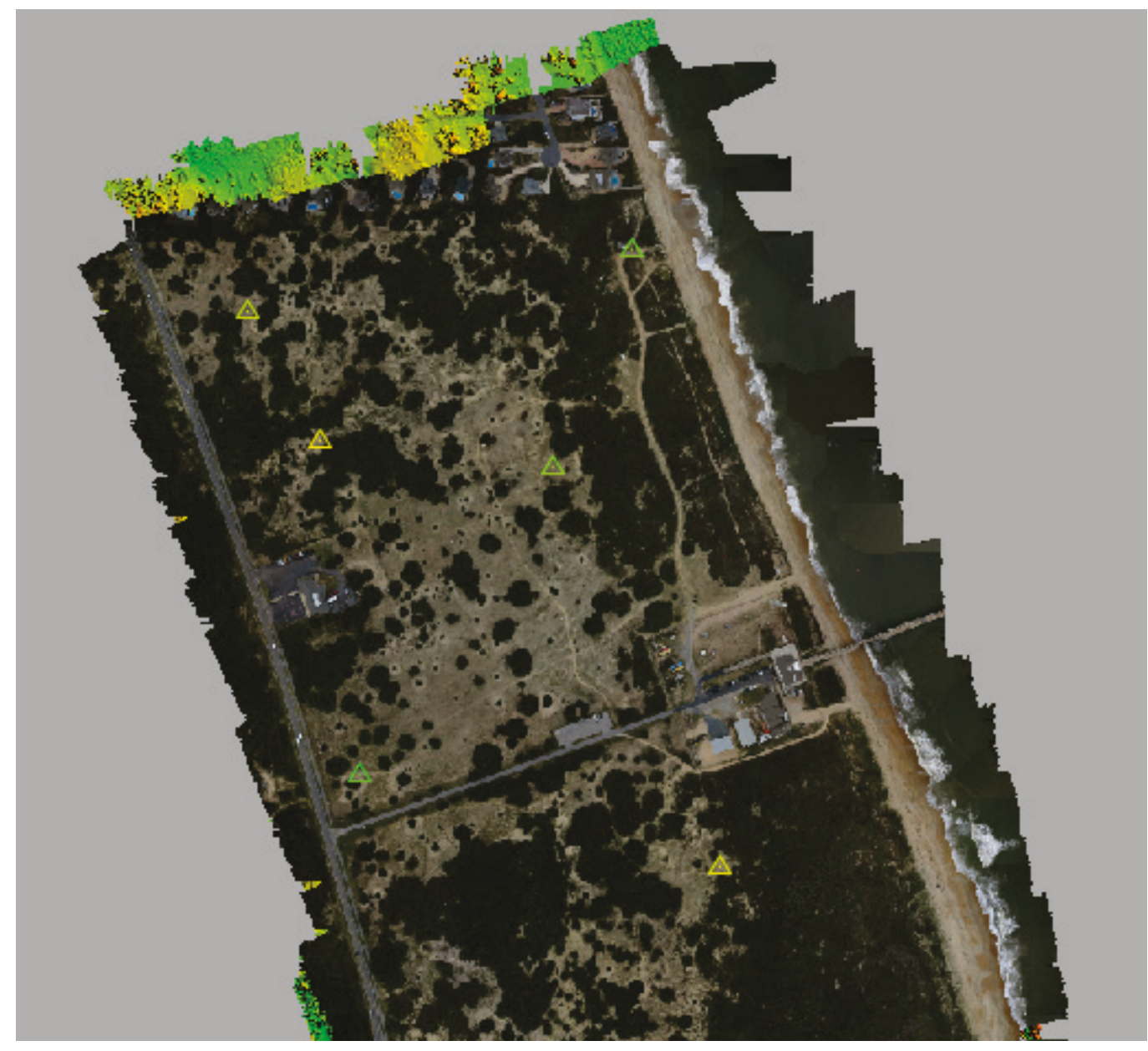


The U.S. Army Engineer Research and Development Center (ERDC) solves the nation's toughest engineering and environmental challenges. ERDC develops innovative solutions in civil and military engineering, geospatial sciences, water resources, and environmental sciences for the Army, the Department of Defense, civilian agencies, and our nation's public good. Find out more at www.erdc.usace.army.mil.

To search for other technical reports published by ERDC, visit the ERDC online library at http://acwc.sdp.sirsi.net/client/default. 


\section{Geospatial Accuracy of Small Unmanned Airborne System Data in the Coastal Environment}

Robert L Fischer, Jeffrey G. Ruby, Aaron J. Armstrong, and Jarrod D. Edwards

Geospatial Research Laboratory

U.S. Army Engineer Research and Development Center

7701 Telegraph Road

Alexandria, VA 22315

Nicholas J. Spore and Katherine L. Brodie

Field Research Facility

U.S. Army Engineer Research and Development Center

1261 Duck Road

Kitty Hawk, NC 27949

Final report

Approved for public release; distribution is unlimited.

Prepared for U.S. Army Corps of Engineers

Washington, DC 20314-1000

Under Project No. 462585, "UAS for Flood Risk Management" 


\section{Abstract}

The purpose of this special report is to document the collection of high spatial resolution image data acquired from an unmanned airborne system (UAS) in a coastal environment over the U.S. Army Corps of Engineers Field Research Facility in Duck, NC, to assess the geospatial accuracy of various software processing packages. Imagery data from two missions (one flight from October 2015 and a second from September 2016) were collected using a fixed-wing SenseFly eBee drone platform. Four commercial processing packages were used to generate standard geospatial products to include digital surface models and orthometric mosaics. Geospatial accuracy was assessed via 11 checkpoints spread throughout the 70 hectare site. Results showed that accuracy differed by software package, which could be partially related to the photogrammetric processing approaches. Three-dimensional root mean square error ranged from 0.54 to 0.06 meter. The study also showed the importance of image collection strategy, camera parameter settings, and ground control point/checkpoint design when attempting to assess geospatial accuracy from UAS platforms in the coastal environment.

DISCLAIMER: The contents of this report are not to be used for advertising, publication, or promotional purposes. Citation of trade names does not constitute an official endorsement or approval of the use of such commercial products. All product names and trademarks cited are the property of their respective owners. The findings of this report are not to be construed as an official Department of the Army position unless so designated by other authorized documents. 


\section{Contents}

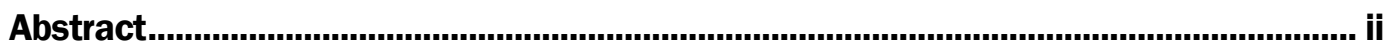

Figures and Tables..................................................................................................................... iv

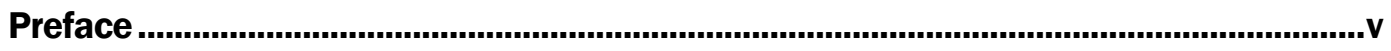

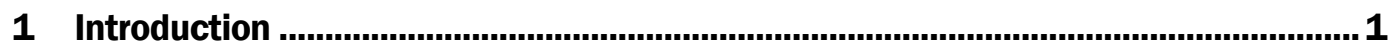

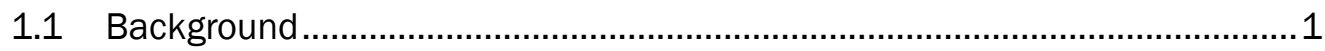

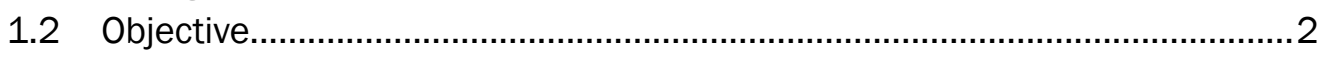

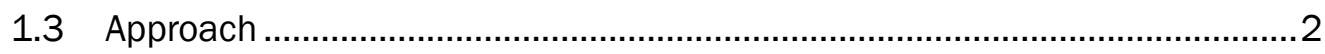

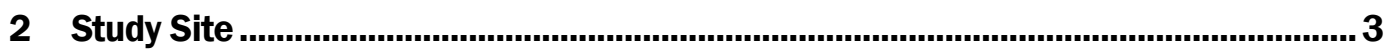

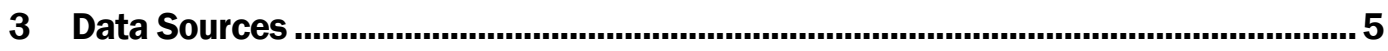

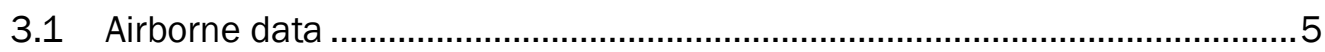

3.2 Ground control ................................................................................ 6

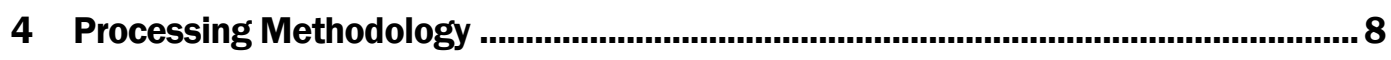

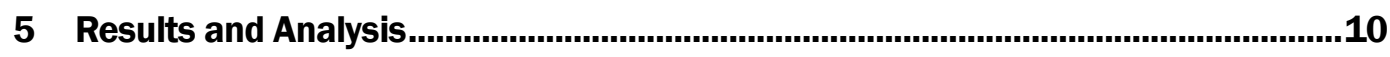

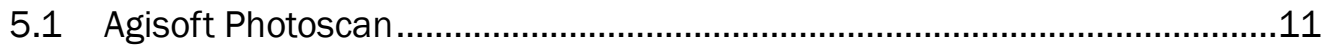

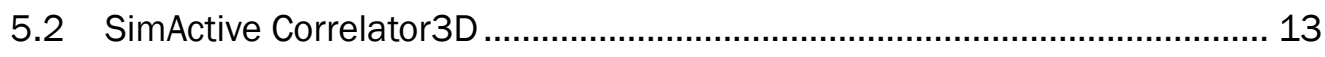

5.3 Bentley ContextCapture ........................................................................ 15

5.4 École Polytechnique Fédérale de Lausanne (EPFL) Pix4D ...........................17

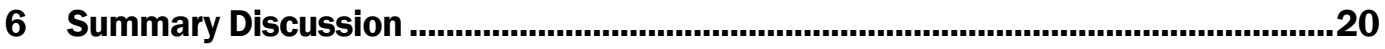

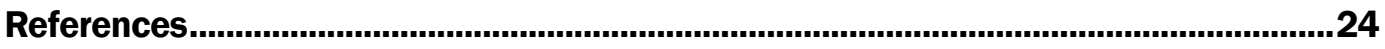

\section{Report Documentation Page}




\section{Figures and Tables}

\section{Figures}

Figure 1. An aeronautical section chart over the USACE FRF facility. The facility location is marked by the red circle

Figure 2. Sample flight plan over the FRF site generated by the SenseFly eMotion flight planning software. In this example flight plan, both east/west and north/south flight lines are shown.

Figure 3. USACE-GRL SenseFly eBee UAS system.

Figure 4. Sample digital surface model over the main FRF buildings from the imagery collected in September 2016, as processed by Correlator3D.

Figure 5. Sample orthomosaic over the main FRF buildings from the imagery collected in September 2016, as processed by Correlator3D.

\section{Tables}

Table 1. Camera settings and flying parameters for the FRF flights.

Table 2. Agisoft Photoscan results from data collected in 2015. All dimensions are in meters.

Table 3. Agisoft Photoscan results from data collected in 2016. All dimensions are in meters.

Table 4. Correlator3D results from data collected in 2015. All dimensions are in meters.

Table 5. Correlator3D results from data collected in 2016. All dimensions are in meters.

Table 6. ContextCapture results from data collected in 2015. All dimensions are in meters.

Table 7. ContextCapture results from data collected in 2016. All dimensions are in meters.

Table 8. Pix4D results from data collected in 2015. All dimensions are in meters.

Table 9. Pix4D results from data collected in 2016. All dimensions are in meters.

Table 10. Summary of results (all error values are in meters). Pixel ground sample distance is $0.035 \mathrm{~m}$. Horizontal accuracy results are color coded as follows: green is Standard High Accuracy; blue is Lower Accuracy; and yellow is poorer than Lower Accuracy. No RMSExy met the requirement for Highest Accuracy. 


\section{Preface}

This study was conducted for the U.S. Army Corps of Engineers under Project No. 462585, "UAS for Flood Risk Management.” This study was funded under the Coastal Ocean Data Systems (CODS) and Flood and Coastal Systems (F\&CS) Research \& Development (R\&D) Programs. F\&CS R\&D is funded by the Flood Risk Management (FRM) business line of the Headquarters, U.S. Army Corps of Engineers (HQUSACE), and is administered by the U.S. Army Engineer Research and Development Center (ERDC), Coastal and Hydraulics Laboratory (CHL), Vicksburg, MS, under the FRM Program of HQUSACE. Mr. Mark S. Roupas is the HQUSACE FRM Business Line manager overseeing F\&CS. Dr. Jeffrey P. Waters was the program manager for CODS, and Dr. Julie Rosati was the Acting program manager for the Flood \& Coastal Systems R\&D Program.

The work was performed by the Geospatial Applications Branch (GAB), of the Research Division, U.S. Army Engineer Research and Development Center, Geospatial Research Laboratory (ERDC-GRL), and the Coastal Observation and Analysis Branch (COAB) of the Flood and Storm Protection Division (CEERD-HF), ERDC Coastal and Hydraulics Laboratory (CHL). At the time of publication of this report, Mr. Todd Sims was Chief, CEERD-TR-A; Ms. Martha Kiene was Chief, CEERD-TR; Dr. Jeffrey Waters was Chief, CEERD-HFA; and Dr. Cary Talbot was Chief, CEERD-HF. Dr. Julie Rosati was the Technical Director for the Flood and Coastal Systems Research \& Development Programs. The Deputy Director of ERDC-CHL was Mr. Jeffrey R. Eckstein, and the Director was Dr. Ty V. Wamsley.

COL Ivan P. Beckman was the Commander of ERDC, and Dr. David W. Pittman was the Director. 


\section{Introduction}

\subsection{Background}

The coastal zone is a dynamic environment that requires temporal monitoring from flexible remote sensing tools. Changing weather, winds, and tides introduce difficulties when attempting to use sensors that are constrained by schedule to include satellite overflight or aircraft with hard collection dates and times. However, these collection requirements are well suited for small unmanned airborne system (UAS) platforms that can be deployed and made operational with minimal notice. Additionally, the low collection altitude, combined with short focal length imagers (often integrated to these small UAS platforms) are capable of producing very high spatial resolution horizontal and vertical data. These data have direct application for addressing many of the questions associated with coastal environments including beach and dune erosion, wetland conditions, impervious surface mapping, and species composition/health.

Along with the growth of small UAS aircraft has been the related development of many processing software packages to exploit these new data sources. Current commercial-off-the-shelf (COTS) and governmentoff-the-shelf software are capable of harnessing the multi-core, multigraphical processing unit architectures. These packages are very efficient at addressing problems that require solving many independent calculations, which is exactly the case with photogrammetric processing. This capability has migrated photogrammetric processing (traditionally executed on high-end, expensive workstations) to low-cost commodity notebook personal computers (PCs).

While most of the COTS tools have the same basic functionality, there are substantial differences with detailed capabilities, cost, ease of use, integration to platforms, and adaption to existing workflows. These parameters will differ by data requirements and final usage. Even within the U.S. Army Corps of Engineers (USACE), different laboratories and sections may desire/require different end products. However, some processes and products are relatively standard across users and applications, specifically the generation of the digital surface/elevation models as well as orthometric mosaics. These were the products generated and analyzed as part of this effort. 


\subsection{Objective}

The purpose of this study was to assess the ability of commonly available COTS software to produce geometrically accurate orthometric mosaics and terrain models from low-altitude UAS imagery. The four software packages selected for this study represent a cross section of use within the community and the USACE. The software packages chosen were (1) Agisoft Photoscan, (2) SimActive Correlator3D, (3) Bentley Context Capture, and (4) École Polytechnique Fédérale de Lausanne (EPFL) Pix4D.

\subsection{Approach}

The UAS data processed by these software packages were collected from a Sensefly eBee UAS over the USACE Field Research Facility (FRF) in October 2015 and September 2016. Ground control had been placed and modified periodically over that time period (unrelated to the eBee flights) and was utilized to perform image mosaic georegistration and evaluate positional accuracy.

The report is organized into the following sections: Chapter 1 provides the introduction; Chapter 2 describes the study site; Chapter 3 gives a background on the airborne and ground control data; Chapter 4 describes the processing methodology; Chapter 5 presents the results and analysis; and Chapter 6 summarizes the results, lessons learned, and potential future efforts. 


\section{Study Site}

The site used for this study was the USACE FRF. Set on a former Navy weapons test site on the North Carolina Outer Banks, the FRF is just north of Duck, NC. Established in 1977, the 70 hectare facility performs research to monitor sand movement, wave forces, water currents, temperatures, and sedimentation. The USACE staff regularly hosts multiple events with scientists from around the world to conduct experiments on wave mechanics, beach erosion, and coastal dynamics. The facility includes a 600-meter (m) pier, a $40 \mathrm{~m}$ observation tower, and multiple amphibious and sea-going vessels. The property spans the entire width of the barrier island, providing an excellent site on which to base remote sensing research in the coastal environment.

Permission to fly UAS aircraft by USACE personnel is obtained through meeting Headquarters-USACE requirements with support from the U.S. Army Aviation Engineering Directorate (AED). Aerial collection from UAS platforms over the FRF facility is relatively straightforward given that the facility is located in Class G airspace (Figures 1 and 2), which allows for the operation of USACE UAS aircraft with the following conditions:

- Airworthiness Release (AWR) for the aircraft (obtained from AED).

- AWR for the operation of an approved aircraft at a particular site (also through AED).

- Flying height below $350 \mathrm{~m}$ above ground level (AGL).

- Within line of sight.

- Certificate of Authorization (CoA) via Glass G Notification.

- Notice to Airman 24-48 hours in advance of flights. 
Figure 1. An aeronautical section chart over the USACE FRF facility. The facility location is marked by the red circle.

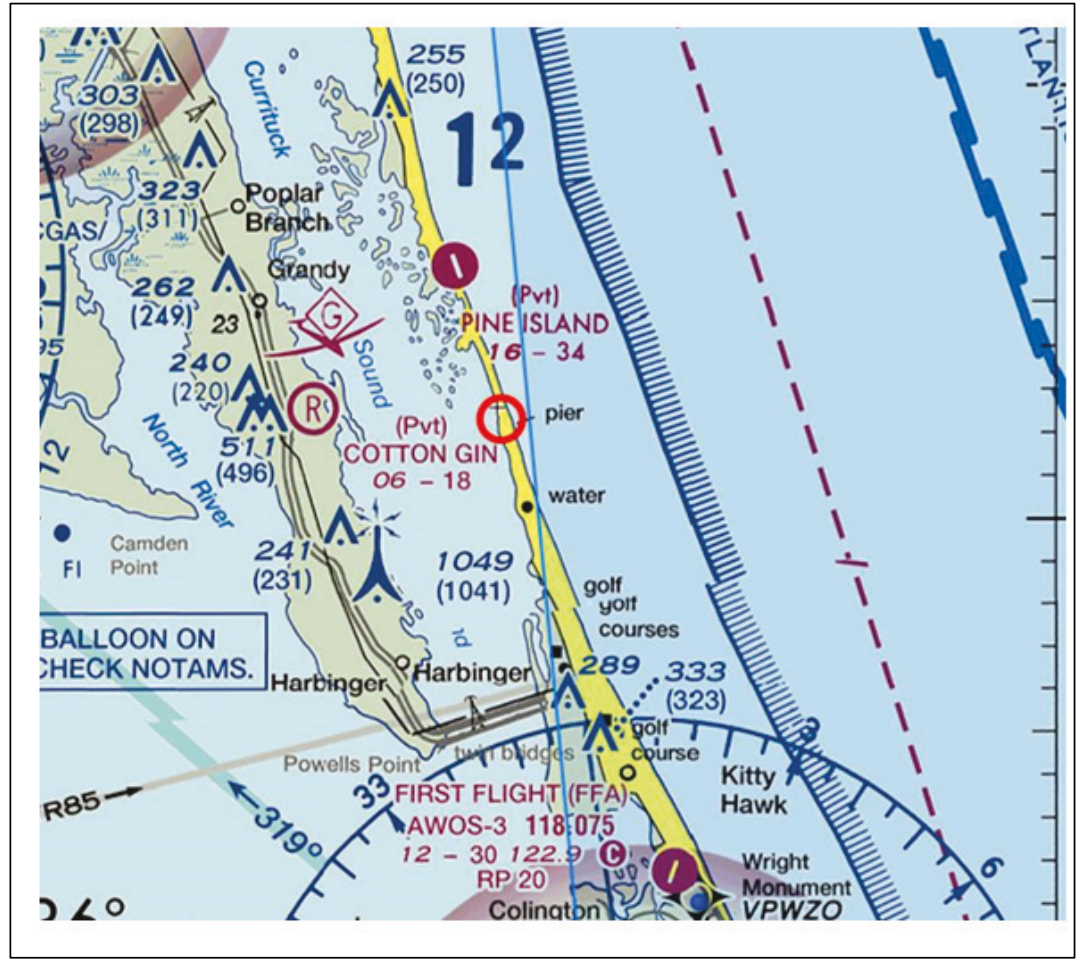

Figure 2. Sample flight plan over the FRF site generated by the SenseFly eMotion flight planning software. In this example flight plan, both east/west and north/south flight lines are shown.

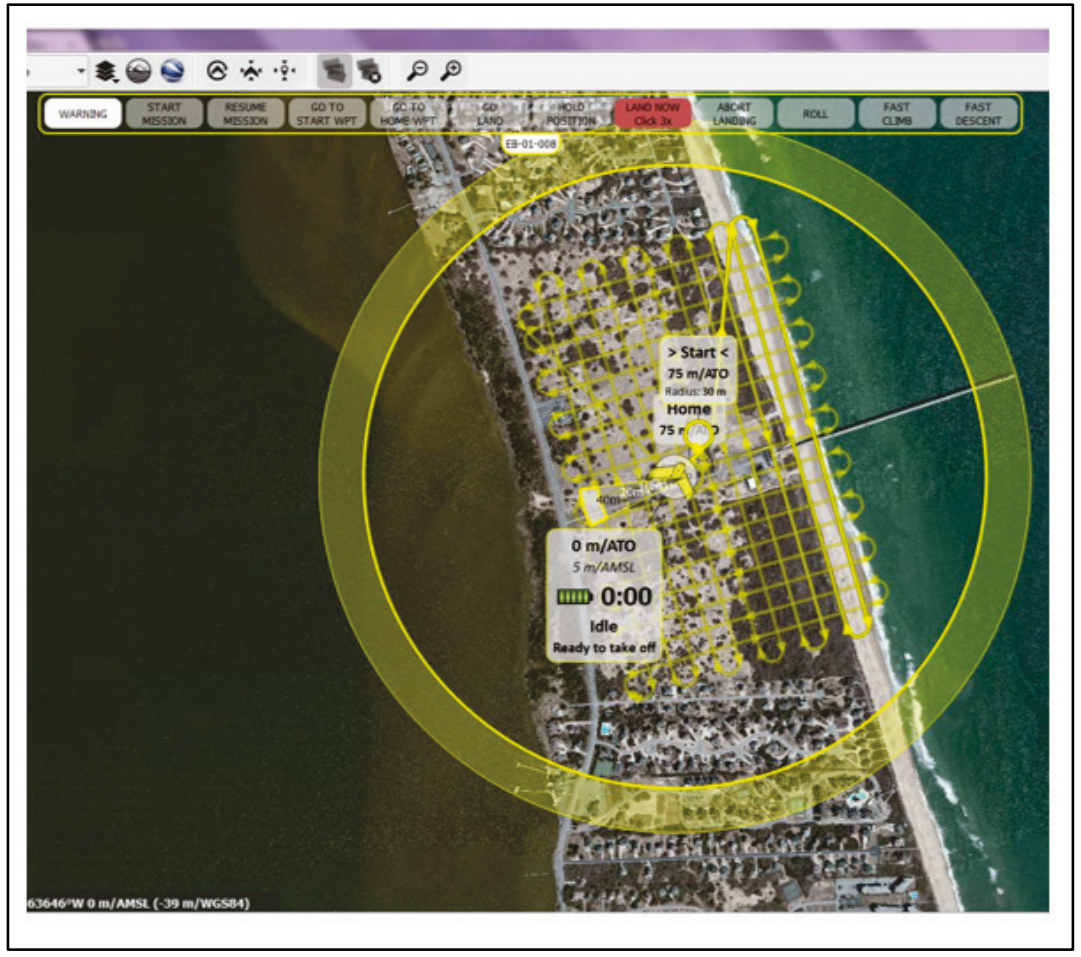




\section{Data Sources}

\subsection{Airborne data}

The UAS-derived data used to generate the geospatial products for this effort were collected using a SenseFly eBee micro-UAS (Sensefly, Geneve, Switzerland), owned and operated by the USACE Geospatial Research Laboratory (GRL). The eBee is a small, fixed-wing, commercially available UAS platform commonly used within the drone mapping community (Figure 3). As of the writing of this report, the cost of a fully operational eBee system (with processing software) was approximately $\$ 23,000.00$. The basic technical and operational parameters for the FRF flights are shown below:

- System Weight: 0.70 kilograms (kg)

- Wingspan: 96 centimeters $(\mathrm{cm})$

- Maximum Flight Time: 50 minutes

- Nominal Cruise Speed: 40-90 kilometers per hour (km/hr)

- Radio Range: $3 \mathrm{~km}$

- Maximum Wind Usage: $45 \mathrm{~km} / \mathrm{hr}$

- Camera: Canon S110 RGB

- Nominal Focal Length: 5.2 millimeters (mm)

- Pixel Array: $4048 \times 3038$

- Pixel Size: 1.86 micrometers $(\mu \mathrm{m})$

- Spatial Resolution at 100 m AGL: $3.6 \mathrm{~cm}$.

Figure 3. USACE-GRL SenseFly eBee UAS system.

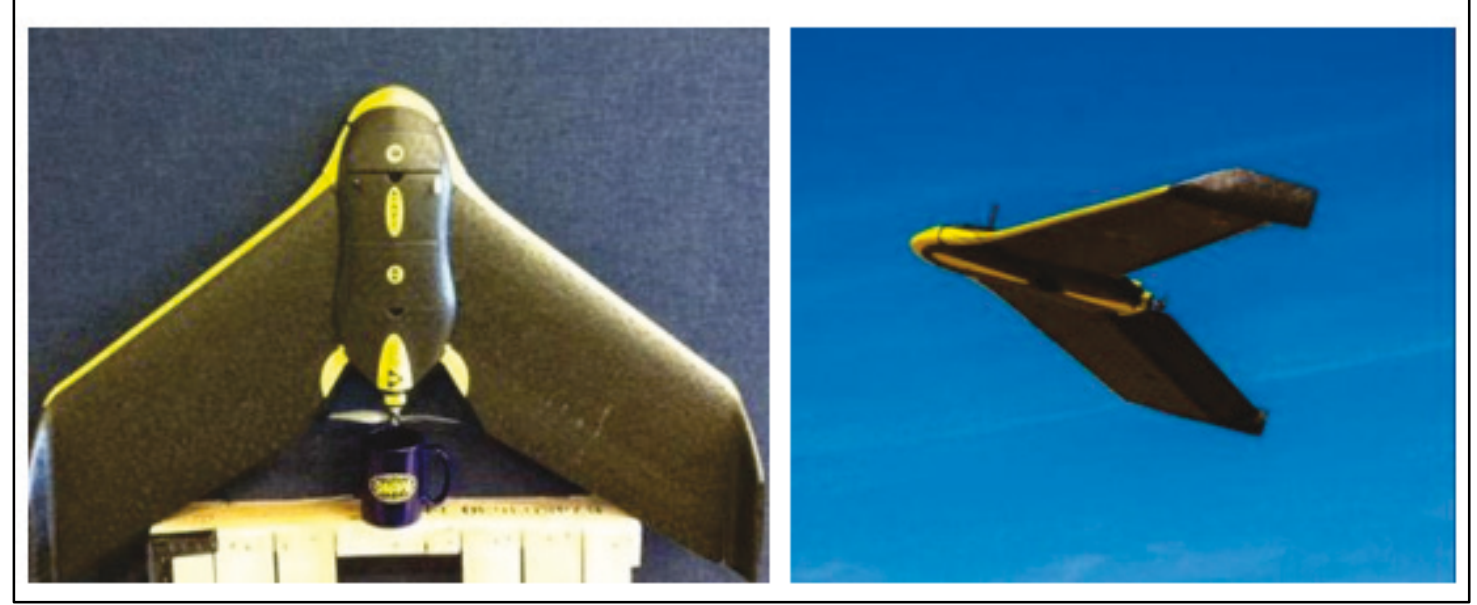


Slightly different camera settings and flying parameters were used between the two collects and are listed in Table 1 below. The camera was set to aperture priority (Av) mode in 2015 to allow the shutter speed to vary to maximize dynamic range. However, in 2016, the shutter was locked to $1 / 1000$ of a second to allow for easier radiometric calibration as part of another study. Furthermore, different flight directions were used between the two dates due to varied wind direction. Also of note were the strong winds during the 2015 collection (gusts $>20 \mathrm{mph}$ ), which required three separate flights to cover the entire FRF facility and resulted in more offnadir images due to substantial aircraft roll.

Table 1. Camera settings and flying parameters for the FRF flights.

\begin{tabular}{|c|c|c|c|c|c|c|}
\hline Date & F-stop & Shutter (sec) & ISO & Fly Height (m) & Flight Direction & \# Images \\
\hline $10 / 29 / 15$ & $\mathrm{f} / 4$ & Vary & 80 & $105 \mathrm{~m}$ & East/West & 264 \\
\hline $09 / 27 / 16$ & $\mathrm{f} / 4$ & $1 / 1000$ & 100 & $110 \mathrm{~m}$ & North/South & 314 \\
\hline
\end{tabular}

\subsection{Ground control}

To geometrically register the final products to absolute coordinates and to assess horizontal and vertical accuracy, a series of ground control points (GCPs) and checkpoints were used. The GCPs consisted of standard photo panels spaced throughout the FRF property. The GCPs were surveyed using a Trimble R10 real-time kinematic Global Navigation Satellite System on a $1.8 \mathrm{~m}$ range pole with a bipod for 3-minute observations. Post processing was performed using the Trimble Business Center to verify accuracy and output final coordinate values in the desired datum and projection. Final horizontal and vertical precision was less than $9 \mathrm{~mm}$ for all points. The horizontal datum was North American Datum 1983 (NAD83) (2011) in North Carolina State Plane (meters). The vertical datum was North American Vertical Datum of 1988 (NAVD88) with Geoid 12B applied. For processing using the COTS photogrammetric packages, European Petroleum Survey Group (EPSG) code 32119 was selected as three of the four packages recognized this definition.

A total of eight, well-spaced GCPs were used to adjust the photo-blocks. As the panels had been placed on the property at various times, only four of the eight GCPs were present in the 2015 data while all eight were present in 2016. At first consideration, utilizing only four GCPs is typically considered too few for a project of this size. However, a primary objective of a more comprehensive study was to test the ability of the COTS software 
to simultaneously solve blocks of photos across multiple dates to track dune loss. Therefore, for three of the four packages studied, control from GCPs found in the 2016 data could be transferred to the 2015 dataset via nearby tie-points that were selected in both dates. This sensor fusion approach allows for better co-registration between datasets while potentially giving up a small amount of absolute ground accuracy (which could be a subject of further study).

To assess the accuracy of the adjustments and data products, checkpoints were selected from additional photo targets as well as identifiable manmade features to include painted lines and pavement intersections. A total of 11 checkpoints were selected throughout the area of interest and surveyed by the same equipment and techniques used for the GCPs. 


\section{Processing Methodology}

Each of the software packages selected for this study use structure-frommotion (SfM) and multi-view stereo algorithms that implement many standard photogrammetric concepts. While specific details are not provided by the vendors for competitive reasons, each package uses highly efficient central processing unit/graphic processing unit computer vision techniques to generate large numbers of image match, or tie-points. These tie-points, which can be supplemented by GCPs, are then used to generate an exterior orientation and interior/optical calibration using a bundleblock adjustment. Final geospatial products can then be developed. The major processing steps are presented below:

- Select project datum and projection.

- Import photos (either joint photographic experts group [JPG] or other image format).

- Extract initial exterior orientation (via Exchangeable Image File Format [EXIF] header or associated text file).

- Perform initial tie-point generation.

- Perform initial bundle adjustment (for interior/optical calibration).

- Add ground control points.

- Perform second bundle adjustment.

- Build digital surface model and bare earth model (optional).

- Create orthophotos and orthomosaics.

Again, the exact steps will vary by vendor package and are dependent upon the final products desired by the user. As an example, Figures 4 and 5 show some typical products generated by Correlator3D. Methods to set final resolutions, formats, and radiometric parameters will differ by package. Terminology and default settings differ between the software packages. An effort was made to standardize the parameters and processes to the extent feasible. However, in the end, there were some unavoidable processing deviations. As a point of interest, surface model and mosaic generation was approximately 4 hours on a Dell Precision notebook PC (M480o, i7 2.5 gigahertz central processing unit, with 32 gigabytes of random access memory) for each of the four software packages.

Not specifically addressed are the editing and error-checking steps. Often these tasks can be time consuming, so quality tools that facilitate these steps are very important and contribute greatly to the overall utility of the software package. 
Figure 4. Sample digital surface model over the main FRF buildings from the imagery collected in September 2016, as processed by Correlator3D.

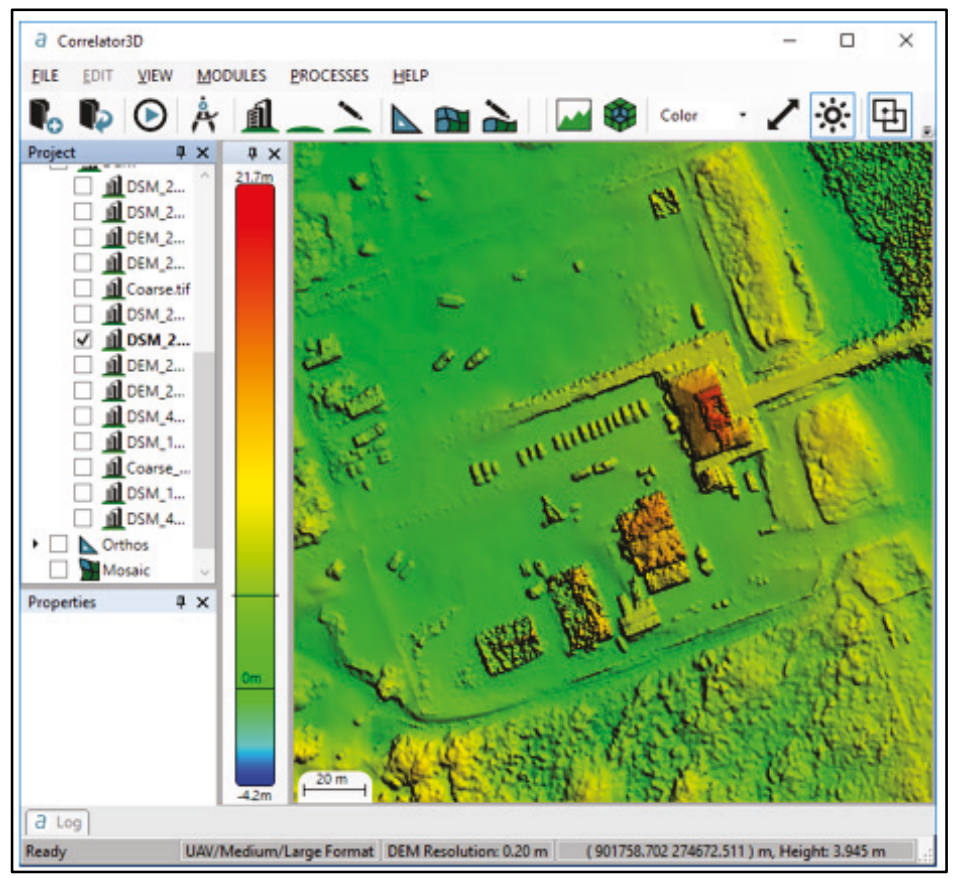

Figure 5. Sample orthomosaic over the main FRF buildings from the imagery collected in September 2016, as processed by Correlator3D.

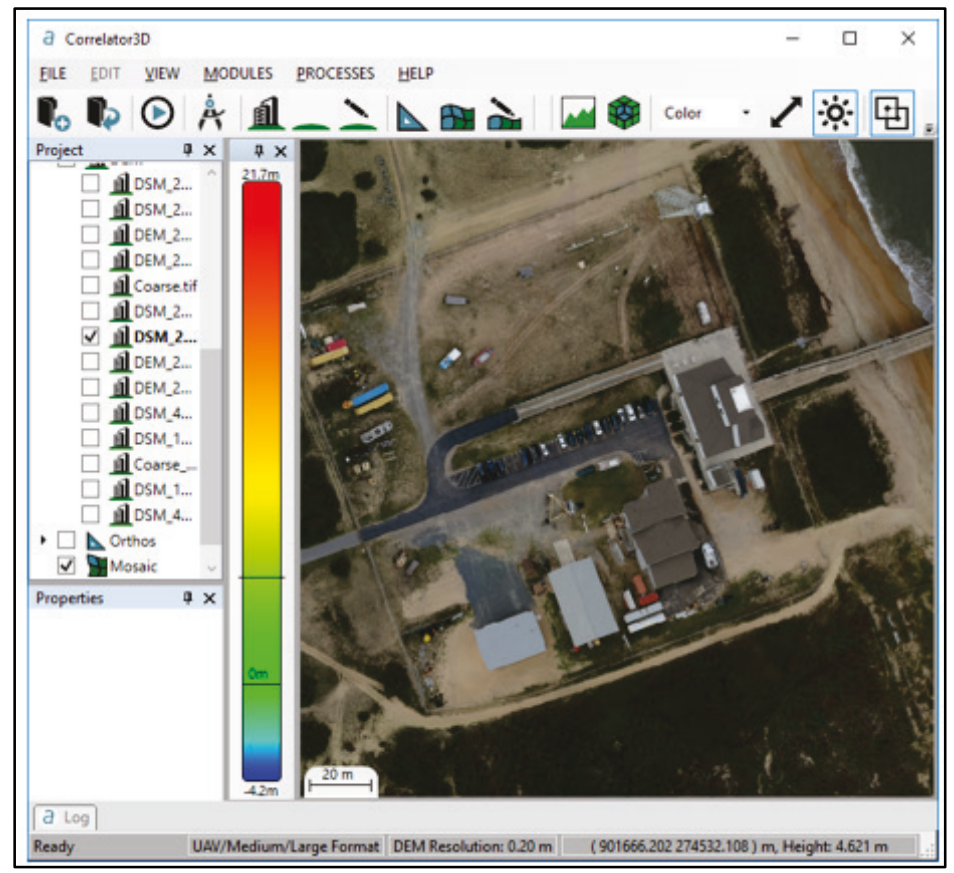




\section{Results and Analysis}

Each of the individual software packages listed in the introduction was reviewed for geospatial accuracy using a customzied Quantum Geographic Information System ver. 2.1 utility (QGIS). While each of them had its own ability to generate checkpoint statistics, the research team could not ascertain how the statistics were generated so opted to output the geospatial products (digital surface models [DSMs] and orthometric mosaics) and then use an accepted standardized process across all the results.

The following procedure was implemented to assess the accuracy of the orthomosaics and DSMs generated from the various software packages:

1. Generate georeferenced tagged image file format orthomosaics and DSMs from the COTS software packages. Unless otherwise specified, the DSM spatial resolution was $10 \mathrm{~cm}$, and the mosaic resolution was $3.5 \mathrm{~cm}$.

2. Ingest orthomosaics and DSMs into the third-party geographic information system package. For this effort, QGIS was used.

3. Create a shapefile of the global positioning system (GPS)-based XYZcoordinates of the checkpoints.

4. Visually find the checkpoint in the orthomosaic using the GPS coordinate as a guide. Build a second shape file with the orthomosaicbased positions.

5. Interpolate the Z-value from the DSM for each XY-coordinate from step 4. For this effort, the Raster Interpolation plugin in QGIS with bilinear interpolation was used.

6. Export shapefile orthomosaic and DSM checkpoint coordinates into a text file.

The text file is then imported into a spreadsheet that contains the surveyed GCP coordinate information and performs the calculations for accuracy assessment as described in USACE Photogrammetric and LiDAR Mapping Engineering Manual (EM) (USACE 2015). The standards described in the USACE EM are identical to those published by the American Society of Photogrammetry and Remote Sensing (ASPRS) (ASPRS 2015).

Of a moderate concern were the relatively few number of checkpoints available. The USACE EM (USACE 2015) suggests 20 checkpoints for non- 
vegetated areas and at least 5 checkpoints in vegetated areas for small projects. The data used for this study were originally collected for other purposes, and at that time the research team did not envision the need for additional checkpoints. This situation will be remedied in future flights.

\subsection{Agisoft Photoscan}

Agisoft Photoscan is arguably the most popular commercial, small UAS mapping processing software package. Photoscan is well suited for creation of terrain surfaces, orthometric mosaics, as well as threedimensional (3D) models. Photoscan is available as a standalone product, but can also be bundled with hardware during the acquisition of the aircraft. Cost at publication is relatively low at approximately $\$ 3,500.00$. Other positive points include the ability to script using Python and execute via a command line interface. A negative is the country of origin (Russia), which could potentially limit installation on certain systems and networks. However, this has not been an issue to date for USACE civil works users.

The 2015 and 2016 datasets were ingested as generally described in Chapter 4 Processing Methodology. All frames were Aligned (Photoscan term for tie-point selection and bundle block adjustment) using aircraft position/orientation and several GCPs. Next, all frames were Optimized (Photoscan's term for auto camera calibration).

After Optimization, the combined data set was divided into two separate data sets, one for each day. After data division, there was no further adjustment of camera frame positions or calibration parameters for either set. Dense point clouds, DSMs, and orthomosaic images were then generated for each day. Horizontal and vertical accuracy of the resultant DSMs and orthomosaics was evaluated using the procedure described in the preceding section.

Tables 2 and 3 below list the accuracy results from the two FRF datasets. 
Table 2. Agisoft Photoscan results from data collected in 2015. All dimensions are in meters.

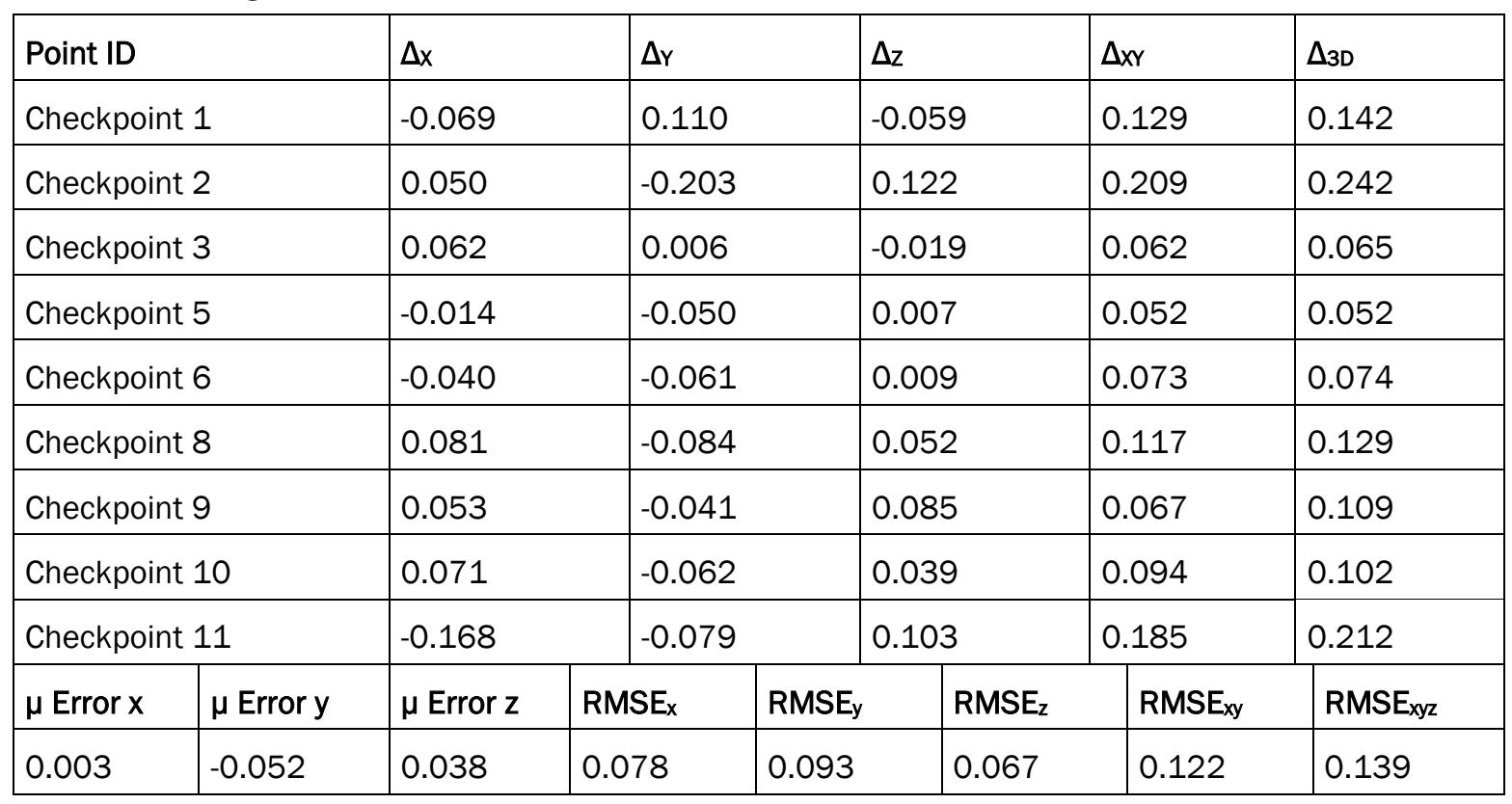

Table 3. Agisoft Photoscan results from data collected in 2016. All dimensions are in meters.

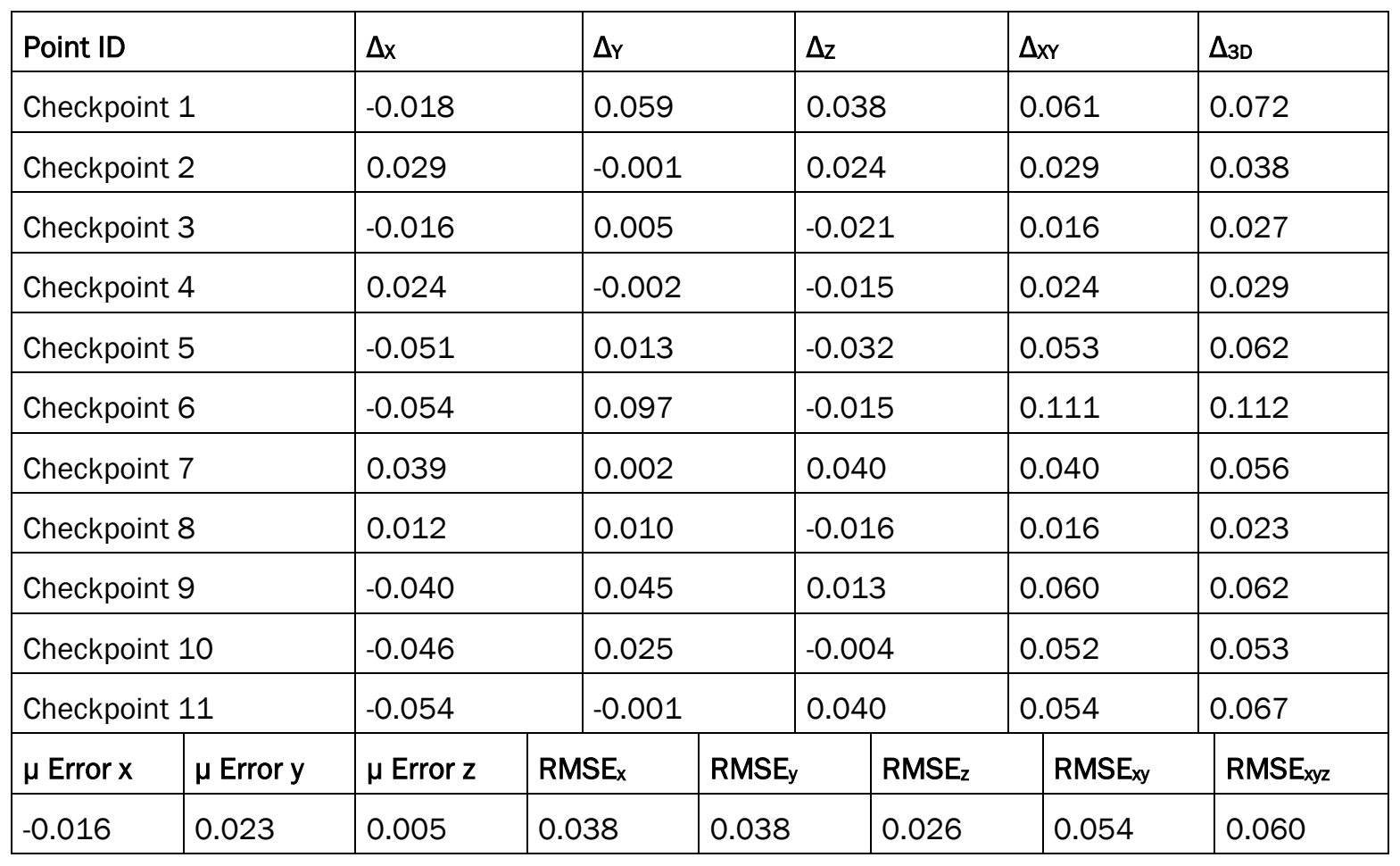


Individual checkpoint accuracies were quite good. Only two of the points from 2015 had 3D errors greater than $15 \mathrm{~cm}$ while all of the 2016 checkpoint accuracies were less than $12 \mathrm{~cm}$. Of the two slightly larger errors from 2015, Checkpoint 11 is located at the extreme southwest corner of the DSM, so a slightly larger error was not unexpected. Potential collection or geometry issues related to Checkpoint 2 were not obvious.

It was expected that co-registration of all frames would lead to similar accuracies for each day, but that was not the case. Data from 2016 were better than data from 2015 ( $5.4 \mathrm{~cm}$ vs. $12 \mathrm{~cm}$ RMSEXY; $2.6 \mathrm{~cm}$ vs. $6.7 \mathrm{~cm}$ RMSEz; 6 cm vs. 14 cm RMSExyz) ${ }^{1}$. Interestingly, accuracy of the independent solutions (not shown), where tie-points were not extracted between the dates, were very close to the combined solutions for each day.

A likely contributing factor to the lower accuracy for the 2015 data set was reduced image quality. The data from 2015 were collected in Av mode with an exposure compensation of zero. Shutter speeds for the data ranged from $1 / 100$ to $1 / 1250$ of a second. Weather conditions on 29 October 2015 were also challenging. Historical data from Kill Devil Hills, First Flight Airport show sustained winds of approximately $10 \mathrm{mph}$ with gusts greater than $20 \mathrm{mph}$. There are numerous oblique/non-nadir frames in the collect where the air frame is rolled substantially during exposure. The combination of camera settings and weather conditions led to multiple blurry and/or over-exposed frames. It is believed this may have led to a reduction in accuracy of the automated computer vision/pattern matching algorithms used to generate frame-to-frame tie-points for image alignment (and subsequent bundle adjustment). Blurry imagery will also lead to imprecise selection of checkpoints during accuracy assessment. However, in general, both the 2015 and 2016 produced good results.

\subsection{SimActive Correlator3D}

Correlator3D by SimActive is another of many machine vision-based COTS photogrammetric processing software packages. Correlator3D is similar to the other packages used in this report in that it ingests UAS imagery and metadata, generates tie-points, allows for the selection of ground-control points, performs a self-calibrating bundle adjustment, and creates a series of output products to include DSMs, bare-earth surface

\footnotetext{
${ }^{1} \mathrm{RMSE}=$ root mean square error.
} 
models, individual orthophotos and composite orthomosaics. Stand-alone version cost was approximately $\$ 7,500.00$ at the time of this report. Licensing is typically node-lock through a dongle that requires some nontrivial administration if the license is to be moved from machine to machine. As the cost is higher than competitors, and with the somewhat cumbersome licensing, Correlator3D is not heavily used within USACE.

Data ingestion and product creation with Correlator3D proceeded as described in Chapter 4 Processing Methodology. The only substantial difference was that the Correlator3D DSM was produced at $20 \mathrm{~cm}$ spatial resolution. This was done because the recommended resolution by the software was $0.14 \mathrm{~cm}$, and test runs at $10 \mathrm{~cm}$ showed residual noise while not resolving terrain features to any more detail.

Accuracy assessment was calculated as presented earlier. Accuracy results for the 2015 and 2016 Correlator3D products are listed in Tables 4 and 5 below.

Table 4. Correlator3D results from data collected in 2015. All dimensions are in meters.

\begin{tabular}{|c|c|c|c|c|c|c|c|}
\hline \multicolumn{2}{|l|}{ Point ID } & $\Delta x$ & \multicolumn{2}{|l|}{$\Delta_{\mathrm{Y}}$} & $\Delta z$ & $\Delta x y$ & $\Delta_{3 \mathrm{D}}$ \\
\hline \multicolumn{2}{|c|}{ Checkpoint 1} & 0.006 & \multicolumn{2}{|l|}{-0.081} & -0.039 & 0.081 & 0.090 \\
\hline \multicolumn{2}{|c|}{ Checkpoint 2} & 0.022 & \multicolumn{2}{|l|}{-0.083} & -0.088 & 0.085 & 0.123 \\
\hline \multicolumn{2}{|c|}{ Checkpoint 3} & 0.022 & \multicolumn{2}{|l|}{0.013} & -0.058 & 0.025 & 0.063 \\
\hline \multicolumn{2}{|c|}{ Checkpoint 4} & 0.036 & \multicolumn{2}{|l|}{-0.056} & 0.018 & 0.067 & 0.069 \\
\hline \multicolumn{2}{|c|}{ Checkpoint 5} & 0.017 & \multicolumn{2}{|l|}{-0.100} & 0.106 & 0.101 & 0.146 \\
\hline \multicolumn{2}{|c|}{ Checkpoint 9} & 0.132 & \multicolumn{2}{|l|}{0.077} & 0.136 & 0.153 & 0.204 \\
\hline \multicolumn{2}{|c|}{ Checkpoint 10} & 0.058 & \multicolumn{2}{|l|}{-0.092} & -0.682 & 0.109 & 0.690 \\
\hline \multicolumn{2}{|c|}{ Checkpoint 11} & -0.158 & \multicolumn{2}{|l|}{-0.116} & 0.061 & 0.196 & 0.205 \\
\hline$\mu$ Error $x$ & $\mu$ Error y & $\mu$ Error $z$ & RMSE $_{x}$ & RMSE $_{y}$ & $\mathrm{RMSE}_{\mathrm{z}}$ & RMSE $_{x y}$ & RMSE $_{x y z}$ \\
\hline 0.017 & -0.055 & -0.068 & 0.078 & 0.082 & 0.253 & 0.113 & 0.277 \\
\hline
\end{tabular}


Table 5. Correlator3D results from data collected in 2016. All dimensions are in meters.

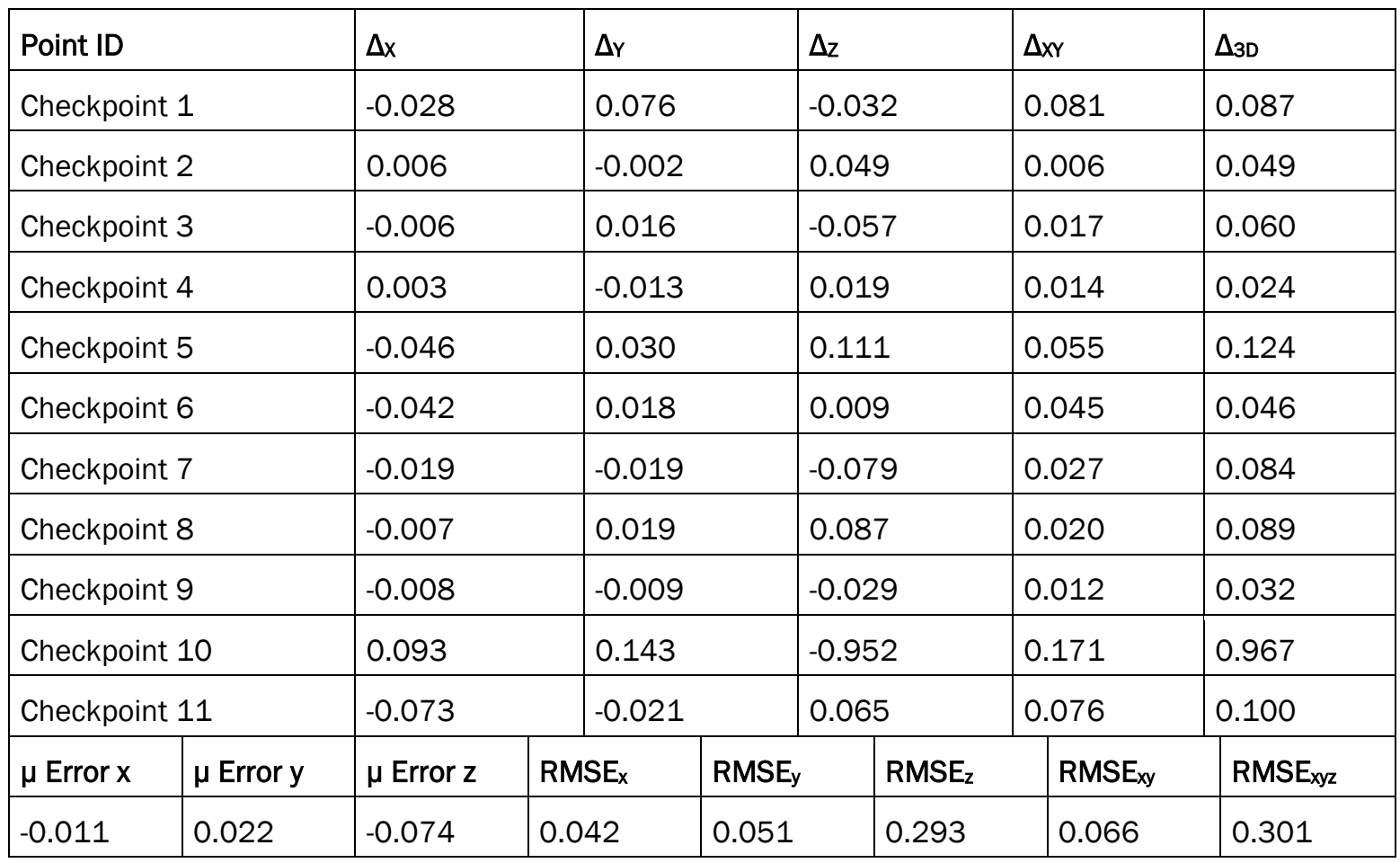

Results from Correlator $3 \mathrm{D}$ were generally similar to those obtained from Photoscan. Checkpoints 9 and 11 are close to the southwest edge for the data products and produced larger errors in the 2015 data. Checkpoint 10 was an interesting case. The point itself was in a relatively open sand area. However, substantial noise was found in a circular area of approximately 10 meters in diameter containing this checkpoint in both the 2015 and 2016 terrain products. This noise caused DSM vertical variations of approximately $1 \mathrm{~m}$ over very small horizontal distances $(\sim 10 \mathrm{~cm})$. The cause of this noise was not readily apparent and represents a concern with this software package. While editing tools do exist that could smooth these areas, this is an extra and potentially time-consuming step and would impact the engineering lineage of the data.

\subsection{Bentley ContextCapture}

ContextCapture is a software utility that processes UAS imagery via SfM techniques to fully textured models. ContextCapture is supported by Bentley Systems, the producers of Microstation. At the time of this report, ContextCapture is part of the USACE Enterprise License Agreement with Bentley and is available free of charge. ContextCapture will run as a standalone application and does not require installation of Microstation 
The FRF data from 2015 and 2016 were processed using the same general approach as with Photoscan and Correlator3D. Steps included the extraction tie-points, solving via a self-calibrating bundle adjustment, adding GCPs, and then resolving. At this point, the combined model was partitioned into two separate projects (2015 and 2016). A DSM and orthomosaic were created for each project. As with Photoscan, each data set was processed independently in ContextCapture, but those results are not included in this report.

Tables 6 and 7 list the accuracy results for ContextCapture. The combined run of ContextCapture were less accurate than the Photoscan and Correlator3D solutions, though results from each day were similar. The largest error component in the 2016 data came from Checkpoint 7 which had an average $3 \mathrm{D}$ error of slightly over $32 \mathrm{~cm}$. A review of this point shows no obvious reason why the point had such a large error.

Checkpoints 1 and 7 fell outside the 2015 data product boundaries while Checkpoints 5, 6, 9, and 11 were outside the 2016 products.

Table 6. ContextCapture results from data collected in 2015. All dimensions are in meters.

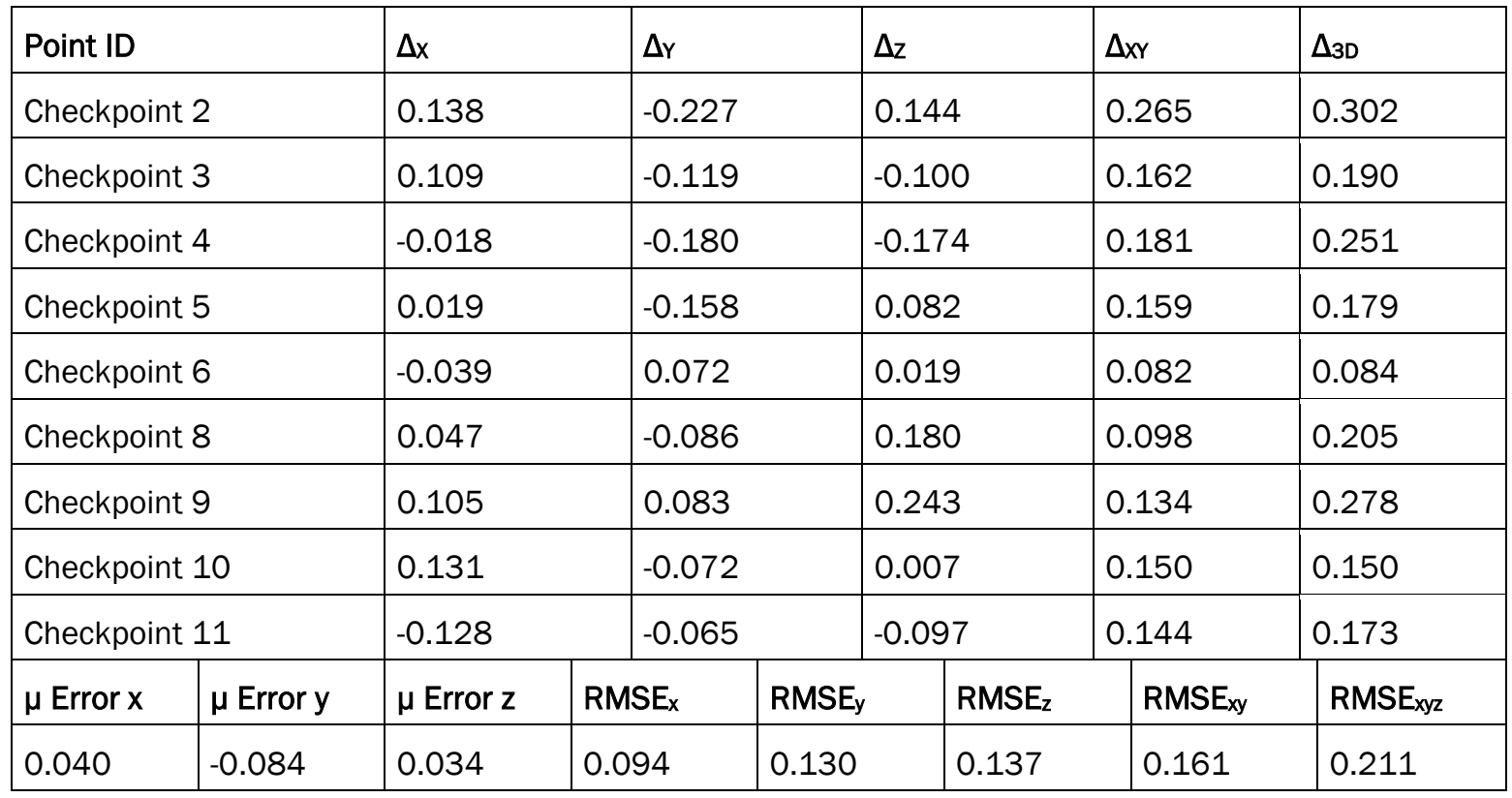


Table 7. ContextCapture results from data collected in 2016. All dimensions are in meters.

\begin{tabular}{|c|c|c|c|c|c|c|c|}
\hline \multicolumn{2}{|l|}{ Point ID } & $\Delta \mathrm{x}$ & \multicolumn{2}{|l|}{$\Delta \mathrm{Y}$} & $\Delta \mathrm{z}$ & $\Delta x y$ & $\Delta_{3 D}$ \\
\hline \multicolumn{2}{|c|}{ Checkpoint 1} & -0.060 & \multicolumn{2}{|l|}{0.062} & -0.134 & 0.086 & 0.159 \\
\hline \multicolumn{2}{|c|}{ Checkpoint 2} & 0.005 & & 0.054 & 0.102 & 0.054 & 0.115 \\
\hline \multicolumn{2}{|c|}{ Checkpoint 3} & 0.148 & \multicolumn{2}{|l|}{-0.093} & -0.078 & 0.175 & 0.191 \\
\hline \multicolumn{2}{|c|}{ Checkpoint 4} & -0.017 & \multicolumn{2}{|l|}{-0.085} & -0.196 & 0.086 & 0.214 \\
\hline \multicolumn{2}{|c|}{ Checkpoint 7} & -0.156 & \multicolumn{2}{|l|}{-0.026} & -0.281 & 0.158 & 0.323 \\
\hline \multicolumn{2}{|c|}{ Checkpoint 8} & -0.068 & \multicolumn{2}{|l|}{0.040} & -0.001 & 0.079 & 0.079 \\
\hline \multicolumn{2}{|c|}{ Checkpoint 10} & 0.010 & \multicolumn{2}{|l|}{-0.040} & 0.131 & 0.041 & 0.138 \\
\hline$\mu$ Error $x$ & $\mu$ Error $y$ & $\mu$ Error $z$ & RMSE $_{x}$ & RMSE $_{\mathrm{y}}$ & $\mathrm{RMSE}_{\mathrm{z}}$ & RMSE $_{x y}$ & RMSE $_{x y z}$ \\
\hline-0.020 & -0.013 & -0.065 & 0.089 & 0.061 & 0.155 & 0.108 & 0.189 \\
\hline
\end{tabular}

Overall, the $3 \mathrm{D}$ error for most points was greater than $15 \mathrm{~cm}$, and several were greater than $30 \mathrm{~cm}$, which was the poorest of the four software packages studied.

\section{4 École Polytechnique Fédérale de Lausanne (EPFL) Pix4D}

Pix4D is a software company based in Lausanne, Switzerland. They were founded in 2011 as a spin-off from EPFL. Pix4D is partnered with SenseFly, which manufactures the eBee sUAS used in this effort. The benefit of their partnership is evident within Pix4D as the software supports all eBee sensors packages, facilitates simple image import via the EXIF header, automatic generation of a Pix4D file (.p4d), and a continually revised database of optimized camera model parameters. The Pix4D software is capable, user friendly, automates some repetitive tasks, and has an intuitive map-based graphical user interface.

From a negative perspective, Pix4D lacks the flexibility of the other software packages that allow a more scientific methodology for processing. The automation, while beneficial to a recreational flyer, constrains functionality that would be useful to a scientist or engineer. Additionally, there are limited options for creating and exporting products at different resolutions. Also, the version of Pix4D used for this effort did not produce datum and projection desired (EPSG 32119). However, once made aware of the issue, EPFL stated additional datum/projection would be supported in future versions of the software. 
An issue encountered with only Pix4D was the inability to extract tiepoints across both dates. This was a function of a slightly different camera setting that did not impact the other software packages. As a result, each of the dates had to be processed independently. Since only four GCPs were visible within the 2015 dataset, some checkpoints were used as GCPs. Likewise, two of the original GCPs were changed to checkpoints.

Accuracy results for the Pix $4 \mathrm{D}$ products are listed in Tables 8 and 9. Overall, results were good and were the most consistent between the two dates.

Table 8. Pix4D results from data collected in 2015. All dimensions are in meters.

\begin{tabular}{|c|c|c|c|c|c|c|c|}
\hline \multicolumn{2}{|l|}{ Point ID } & $\Delta \mathrm{x}$ & \multicolumn{2}{|l|}{$\Delta \mathrm{Y}$} & $\Delta \mathrm{z}$ & $\Delta x y$ & $\Delta_{3 \mathrm{D}}$ \\
\hline \multicolumn{2}{|l|}{ GCP 104} & -0.122 & \multicolumn{2}{|l|}{0.124} & -0.592 & 0.174 & 0.617 \\
\hline \multicolumn{2}{|l|}{ GCP 110} & -0.010 & \multicolumn{2}{|l|}{-0.062} & 0.065 & 0.063 & 0.090 \\
\hline \multicolumn{2}{|c|}{ Checkpoint 3} & -0.054 & \multicolumn{2}{|l|}{0.004} & -0.515 & 0.054 & 0.518 \\
\hline \multicolumn{2}{|c|}{ Checkpoint 5} & -0.056 & \multicolumn{2}{|l|}{-0.048} & -0.474 & 0.074 & 0.479 \\
\hline \multicolumn{2}{|c|}{ Checkpoint 8} & 0.013 & \multicolumn{2}{|l|}{-0.029} & -0.300 & 0.031 & 0.302 \\
\hline \multicolumn{2}{|c|}{ Checkpoint 10} & 0.068 & \multicolumn{2}{|l|}{-0.028} & -0.064 & 0.073 & 0.097 \\
\hline \multicolumn{2}{|c|}{ Checkpoint 11} & -0.124 & \multicolumn{2}{|l|}{-0.037} & -0.675 & 0.130 & 0.687 \\
\hline$\mu$ Error $x$ & $\mu$ Error y & $\mu$ Error $z$ & RMSE $_{\mathrm{x}}$ & RMSEy $_{\mathrm{y}}$ & $\mathrm{RMSE}_{\mathrm{z}}$ & RMSE $_{x y}$ & RMSE $_{x y z}$ \\
\hline-0.041 & -0.011 & -0.365 & 0.077 & 0.059 & 0.446 & 0.097 & 0.457 \\
\hline
\end{tabular}


Table 9. Pix4D results from data collected in 2016. All dimensions are in meters.

\begin{tabular}{|c|c|c|c|c|c|c|c|}
\hline \multicolumn{2}{|l|}{ Point ID } & $\Delta x$ & \multicolumn{2}{|l|}{$\Delta \mathrm{Y}$} & $\Delta \mathrm{z}$ & $\Delta x y$ & $\Delta_{3 \mathrm{D}}$ \\
\hline \multicolumn{2}{|c|}{ Checkpoint 1} & -0.031 & \multicolumn{2}{|l|}{0.060} & -0.672 & 0.067 & 0.675 \\
\hline \multicolumn{2}{|c|}{ Checkpoint 2} & -0.004 & \multicolumn{2}{|l|}{-0.018} & -0.547 & 0.019 & 0.547 \\
\hline \multicolumn{2}{|c|}{ Checkpoint 3} & -0.009 & \multicolumn{2}{|l|}{0.080} & -0.536 & 0.080 & 0.542 \\
\hline \multicolumn{2}{|c|}{ Checkpoint 4} & 0.042 & \multicolumn{2}{|l|}{-0.015} & -0.546 & 0.044 & 0.548 \\
\hline \multicolumn{2}{|c|}{ Checkpoint 5} & -0.036 & \multicolumn{2}{|l|}{0.032} & -0.530 & 0.048 & 0.532 \\
\hline \multicolumn{2}{|c|}{ Checkpoint 6} & -0.019 & \multicolumn{2}{|l|}{-0.011} & -0.464 & 0.022 & 0.464 \\
\hline \multicolumn{2}{|c|}{ Checkpoint 7} & 0.049 & \multicolumn{2}{|l|}{0.043} & -0.523 & 0.066 & 0.527 \\
\hline \multicolumn{2}{|c|}{ Checkpoint 8} & 0.003 & \multicolumn{2}{|l|}{0.005} & -0.547 & 0.006 & 0.547 \\
\hline \multicolumn{2}{|c|}{ Checkpoint 9} & -0.020 & 0.039 & & -0.418 & 0.044 & 0.420 \\
\hline Checkpoir & & -0.026 & 0.027 & & -0.533 & 0.037 & 0.534 \\
\hline Checkpoir & & -0.120 & 0.062 & & -0.574 & 0.135 & 0.589 \\
\hline$\mu$ Error $x$ & $\mu$ Error y & $\mu$ Error z & $\mathrm{RMSE}_{\mathrm{x}}$ & RMSE $_{y}$ & $\mathrm{RMSE}_{\mathrm{z}}$ & RMSE $_{x y}$ & RMSE $_{x y z}$ \\
\hline-0.016 & 0.028 & -0.535 & 0.045 & 0.042 & 0.539 & 0.062 & 0.542 \\
\hline
\end{tabular}




\section{Summary Discussion}

As described in earlier sections, the original purpose of the FRF eBee data was not horizontal and vertical accuracy assessment; therefore, the number of GCPs and checkpoints did not meet the requirements as described in the USACE EM (USACE 2015). However, enough points were available to test the software packages and generate preliminary results. Table 10 summarizes statistics for the 2015 and 2016 deployments for each of the four COTS packages investigated. A few trends are immediately obvious. First, the accuracy results from 2016 are better than 2015. The only potential outlier is the result for Pix $4 \mathrm{D}$, but this was primarily the $\mathrm{Z}$ error, which could be a bias due to incomplete understanding of the processing defaults. As previously noted, the two primary reasons cited for the poorer results with the 2015 data was blur induced by the slow shutter speed and the instances of more oblique frames caused by aircraft roll (more oblique data have coarser spatial resolution and poorer geometric calibration). The blur and reduced resolution will result in larger errors during tie-point generation, GCP selection, and checkpoint identification. Additionally, each dataset did not use the exact number of checkpoints as differences in spatial size of the products caused some checkpoints to be off the edge of the $\mathrm{DSM} /$ mosaics on certain COTS package results, which were not consistent.

The USACE EM (USACE 2015) specifies three uses or classes of digital horizontal data that are a function of the pixel ground sample distance (GSD). Class 1 is the Highest Accuracy where RMSEXY $\leq 1.414^{*} \mathrm{GSD}$; Class 2 is the Standard High Accuracy (RMSEXY $\leq 1.414^{*} 2^{*} \mathrm{GSD}$ ); and Lower Accuracy (RMSEXY $\leq 1.414^{*} 3^{*} \mathrm{GSD}$ ). Class 2 is considered typical for a large majority of existing USACE projects. These standards are generally proposed for well-calibrated large- and medium-format cameras, not specifically the point and shoot cameras utilized in COTS small UAS platforms. However, these standards do represent an objective threshold for product quality. 
Table 10. Summary of results (all error values are in meters). Pixel ground sample distance is $0.035 \mathrm{~m}$. Horizontal accuracy results are color coded as follows: green is Standard High Accuracy; blue is Lower Accuracy; and yellow is poorer than Lower Accuracy. No RMSExy met the requirement for Highest Accuracy.

\begin{tabular}{|l|l|l|l|l|l|l|l|l|l|}
\hline Collect & Chk. Pts. & $\mu$ Err. $x$ & $\mu$ Err. $y$ & $\mu$ Err. $z$ & RMSE $_{x}$ & RMSE $_{y}$ & RMSE $_{x y}$ & RMSE $_{z}$ & RMSE $_{x y z}$ \\
\hline 2015 Agisoft & 9 & 0.003 & -0.052 & 0.038 & 0.078 & 0.093 & 0.122 & 0.067 & 0.139 \\
\hline 2016 Agisoft & 11 & -0.016 & 0.023 & 0.005 & 0.038 & 0.038 & 0.054 & 0.026 & 0.060 \\
\hline 2015 Corr3D & 8 & 0.017 & -0.055 & -0.068 & 0.078 & 0.082 & 0.113 & 0.253 & 0.277 \\
\hline 2016 Corr3D & 11 & -0.011 & 0.022 & -0.074 & 0.042 & 0.051 & 0.066 & 0.293 & 0.301 \\
\hline 2015 Bentley & 9 & 0.040 & -0.084 & 0.034 & 0.094 & 0.130 & 0.161 & 0.137 & 0.211 \\
\hline 2016 Bentley & 7 & -0.020 & -0.013 & -0.065 & 0.089 & 0.061 & 0.108 & 0.155 & 0.189 \\
\hline 2015 Pix4D & 7 & -0.041 & -0.011 & -0.365 & 0.077 & 0.059 & 0.097 & 0.446 & 0.457 \\
\hline 2016 Pix4D & 11 & -0.016 & 0.028 & -0.535 & 0.045 & 0.042 & 0.062 & 0.539 & 0.542 \\
\hline
\end{tabular}

Overall, the 2016 Agisoft Photoscan data produced the best horizontal accuracy results followed closely by Pix4D and Correlator 3D. Review of Table 10 shows that the 2016 data met the Standard High Accuracy requirements for all four software packages except Bentley ContextCapture, where the RMSExy of $10.8 \mathrm{~cm}$ was only slightly higher than the class limit of $9.9 \mathrm{~cm}$. As noted several times previously, the 2015 results were poorer than 2016. Horizontal 2015 data from Pix4D barely met the Standard High Accuracy metric. Photoscan and Correlator 3D met the requirements for Lower Accuracy, while Bentley ContextCapture failed to meet that level.

Vertical accuracy requirements are broken out into vegetated and nonvegetated areas. For the FRF collections, GCPs and checkpoints were generally in flat open areas, either asphalt or sand, so requirements for non-vegetated areas would be used. The USACE Photogrammetry and LiDAR manual (USACE 2015) lists multiple Vertical Accuracy Classes that are labeled by RMSEz achieved by the data (USACE, 2015). For instance, the 2016 Agisoft Photoscan Vertical Accuracy Class would be listed as " 3 $\mathrm{cm}$," which is the closest round number that is greater than the achieved result of $2.6 \mathrm{~cm}$. Through similar analysis, the 2015 Bentley Context Capture Vertical Accuracy Class would likely be " $15 \mathrm{~cm}$ " (calculated RMSEz of $13.7 \mathrm{~cm}$ ).

Overall, vertical accuracy was consistent between 2015 and 2016 products from the same software package. The only outlier was Agisoft Photoscan, which produced an approximately three times poorer RMSEz in 2015 
compared to 2016. However, these numbers are both quite small, so both should be considered excellent. The best results were obtained from Agisoft Photoscan followed by Bentley ContextCapture. Correlator3D $\mathrm{RMSE}_{z}$ results were heavily influenced by computational noise in the DSMs, where a few checkpoints contributed to the majority of the RMSEz magnitude (as seen in Tables 4 and 5). Pix4D showed the poorest vertical accuracy results. Interestingly, unlike the other software packages, an overall bias was shown in the Z-value (as seen in the Mean Error Z column). The exact cause of the bias was not immediately identified. There is a possibility that modification of weights in the Z-dimension of the GCPs could reduce or remove this bias. This will require additional experimentation with Pix4D to make these proposed processing changes. If successful, overall results for Pix4D (horizontal and vertical) could be very promising.

As is often the case with applied research and development efforts, it becomes obvious that aspects of the effort could have been improved with modifications to data acquisition, sensor calibration, and ground-truth collection. A critical issue that hampered the analysis throughout the effort was the blurred images from 2015 primarily caused by long shutter times. Implementing standard camera settings that conform to lighting conditions should solidify the understanding of achievable accuracies. The following additional recommendations should improve the quality and confidence of the results:

- Additional GCPs established uniformly throughout the collection area.

- Additional checkpoints spread uniformly throughout the collection area. Check points should also be collected within vegetated regions to assess vertical accuracy in these zones.

- Collect higher accuracy GCPs and checkpoints.

- Insure GCPs/checkpoints are not near the edge of the geospatial products. This can be accomplished by planning image collection to go well past the project boundaries.

- Modification of processing strategy. Include the ability to remove frames with poor geometric or radiometric quality.

- Study the impact of image resolution and collection overlap on geospatial accuracy (also as a function of collection time and cost).

The team has a unique opportunity to build upon the results of these efforts and implement some, if not all, of the recommendations suggested 
above. Future collections are planned through 2020 as part of a multi-year research effort. In addition to additional datasets, the research team will have the opportunity to test new aircraft, sensors, processing methodologies, and collection strategies. The results will provide critical information on how this data type can be used for coastal monitoring, flood risk management, and other USACE missions. 


\section{References}

American Society of Photogrammetry and Remote Sensing (ASPRS). 2015. ASPRS positional accuracy standards for digital geospatial data. Photogrammetric Engineering and Remote Sensing 81(3): A1-A26.

U.S. Army Corps of Engineers (USACE). 2015. Photogrammetric and LiDAR Mapping. EM 1110-1-1000. Washington, DC: U.S. Army Corps of Engineers. 


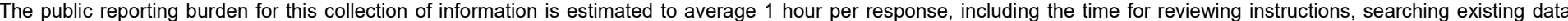

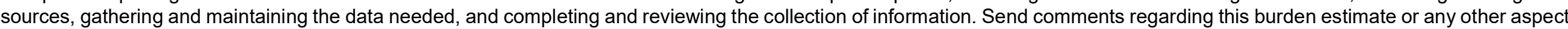

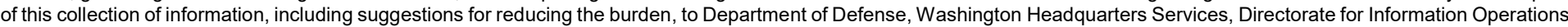

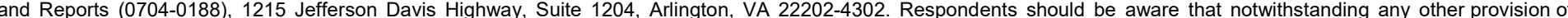
law, no person shall be subject to any penalty for failing to comply with a collection of information if it does not display a currently valid OMB control number.

PLEASE DO NOT RETURN YOUR FORM TO THE ABOVE ADDRESS.

\begin{tabular}{l|l|l}
\hline $\begin{array}{l}\text { 1. REPORT DATE } \\
\text { February } 2019\end{array}$ & $\begin{array}{l}\text { 2. REPORT TYPE } \\
\text { Final Report }\end{array}$ & 3. DATES COVERED (FrOm - To) \\
\hline
\end{tabular}

\section{TITLE AND SUBTITLE}

Geospatial Accuracy of Small Unmanned Airborne System Data in the Coastal

Environment

5a. CONTRACT NUMBER

5b. GRANT NUMBER

5c. PROGRAM ELEMENT NUMBER

5d. PROJECT NUMBER

462585

5e. TASK NUMBER

5f. WORK UNIT NUMBER

8. PERFORMING ORGANIZATION REPORT NUMBER

U.S. Army Engineer Research and

Development Center

1261 Duck Road

Kitty Hawk, NC 27949

ERDC SR-19-1

U.S. Army Engineer Research and

Development Center

7701 Telegraph Road

Alexandria, VA 22315

9. SPONSORING/MONITORING AGENCY NAME(S) AND ADDRESS(ES)

U.S. Army Corps of Engineers

Washington, DC 20314-1000

10. SPONSOR/MONITOR'S ACRONYM(S)

USACE

11. SPONSOR/MONITOR'S REPORT NUMBER(S)

12. DISTRIBUTION/AVAILABILITY STATEMENT

Approved for public release; distribution is unlimited.

\section{SUPPLEMENTARY NOTES}

\section{ABSTRACT}

The purpose of this special report is to document the collection of high spatial resolution image data acquired from an unmanned airborne system (UAS) in a coastal environment over the U.S. Army Corps of Engineers Field Research Facility in Duck, NC, to assess the geospatial accuracy of various software processing packages. Imagery data from two missions (one flight from October 2015 and a second from September 2016) were collected using a fixed-wing SenseFly eBee drone platform. Four commercial processing packages were used to generate standard geospatial products to include digital surface models and orthometric mosaics. Geospatial accuracy was assessed via 11 checkpoints spread throughout the 70 hectare site. Results showed that accuracy differed by software package, which could be partially related to the photogrammetric processing approaches. Three-dimensional root mean square error ranged from 0.54 to 0.06 meter. The study also showed the importance of image collection strategy, camera parameter settings, and ground control point/checkpoint design when attempting to assess geospatial accuracy from UAS platforms in the coastal environment.

\section{SUBJECT TERMS}

Aerial photography, Data collection platforms, Geospatial data, Micro air vehicles, Remote sensing

\section{SECURITY CLASSIFICATION OF:}

\begin{tabular}{|l|c|c|c|} 
a. REPORT & b. ABSTRACT & c. THIS PAGE & ABSTRACT \\
Unclassified & Unclassified & Unclassified & SAR
\end{tabular}

18. NUMBER OF PAGES

32 19a. NAME OF RESPONSIBLE PERSON

Robert L. Fischer

19b. TELEPHONE NUMBER (Include area code) 703-428-6698 